\title{
Anti-hypertensive medications and injurious falls in an older population of low socioeconomic status: a nested case- control study
}

Zafirah Banu ${ }^{1+}$, Ka Keat Lim²+ ${ }^{2+}$, Yu Heng Kwan², Kai Zhen Yap ${ }^{1}$, Hui Ting Ang ${ }^{1}$, Chuen Seng Tan ${ }^{3}$, Warren Fong ${ }^{5,6,7}$, Julian Thumboo 2,5 Kheng Hock Lee ${ }^{4,6}$, Truls Ostbye ${ }^{2}$ and Lian Leng Low ${ }^{4,6^{*}}$

\begin{abstract}
Background: This study aimed to determine whether the number of anti-hypertensive medication classes or any change in anti-hypertensive medication were associated with injurious fall among the community-dwelling older population of low socioeconomic status.

Methods: Using data from electronic medical records, we performed a nested case-control study among older Singapore residents $(\geq 60)$ of low socioeconomic status $(N=210)$. Controls $(n=162)$ were matched to each case $(n=48)$ by age and gender. Variables with $p<0.10$ in univariate analysis were included in multivariate analysis. We used conditional logistic regression to assess the associations of the number of anti-hypertensive medication classes and change in anti-hypertensive medication with injurious falls. We also performed stepwise regressions as sensitivity analyses. $p<0.05$ was considered statistically significant.

Results: The mean $( \pm S D)$ age of participants was 78.1 ( \pm 8.33) years; 127 (60.4\%) were female, 189 (90.0\%) were Chinese. Those on $\geq 2$ anti-hypertensive medication classes had an increased risk of experiencing an injurious fall compared to those not on any anti-hypertensive medication ( $\mathrm{OR}=5.45 ; \mathrm{Cl}: 1.49-19.93 ; p=0.01$ ). Among those who were taking anti-hypertensive medication, those who had a change in the medication 180-day prior to injurious fall had a significantly increased risk of experiencing an injurious fall compared to those that did not report any change in anti-hypertensive medication $(\mathrm{OR}=3.88$; $\mathrm{Cl}: 1.23-12.19 ; p=0.02)$. Sensitivity analyses generated consistent findings.

Conclusion: Both $\geq 2$ anti-hypertensive medication classes and change in anti-hypertensive medication were associated with an increased risk of experiencing an injurious fall among the older population of low socioeconomic status. Our findings could guide prescribers to exercise caution in the initiation of anti-hypertensive medications or in making medication changes, especially among the older population of low socioeconomic status.
\end{abstract}

Keywords: Aged, Antihypertensive agents, Falls, Socio-economic status

\footnotetext{
* Correspondence: low.lian.leng@singhealth.com.sg

${ }^{\dagger}$ Zafirah Banu and Ka Keat Lim contributed equally to this work.

${ }^{4}$ Department of Family Medicine and Continuing Care, Singapore General

Hospital, Singapore, Republic of Singapore

${ }^{6}$ Duke-NUS Medical School, Singapore, Republic of Singapore

Full list of author information is available at the end of the article
}

(c) The Author(s). 2018 Open Access This article is distributed under the terms of the Creative Commons Attribution 4.0 International License (http://creativecommons.org/licenses/by/4.0/), which permits unrestricted use, distribution, and reproduction in any medium, provided you give appropriate credit to the original author(s) and the source, provide a link to the Creative Commons license, and indicate if changes were made. The Creative Commons Public Domain Dedication waiver (http://creativecommons.org/publicdomain/zero/1.0/) applies to the data made available in this article, unless otherwise stated. 


\section{Background}

Falling is a common and severe problem faced by the older population worldwide with $28-35 \%$ of communitydwelling older adults $>64$ years and $32-42 \%$ of those $>$ 70 years estimated to experience at least one fall each year [1]. This has significant social, economic and health implications. Falls result in increased morbidity and mortality, with approximately $10 \%$ of falls leading to serious injuries, such as fractures, intracranial bleeding, serious lacerations and even death [2]. Besides higher healthcare utilization due to falls-related injuries [3], older adults may also experience psychological damages that result in self-imposed limitation in mobility, increased dependency on others for activities of daily living, depression and anxiety [4]. This leads to higher psychological and economic burden for the caregivers and the country [5].

While numerous studies have examined the association between anti-hypertensive medications and falls, most studies only focused on specific classes of anti-hypertensive. Existing systematic reviews and meta- analyses of these studies found weak or no association between the different anti-hypertensive classes and falls [6-8].

Recent evidence suggests that intensity of treatment $[9,10]$ or changes in anti-hypertensive medication [11] may be associated with falls. This is plausible as anti-hypertensive treatment intensity and changes in anti-hypertensive medication have been associated with orthostatic hypotension [12] and neurological side effects [11] which could lead to falls.

Our study aimed to examine whether a higher number of anti-hypertensive medication classes or a recent change in anti-hypertensive medication was associated with injurious falls, defined as falls that required medical services. The focus on injurious falls is due to its direct implication on healthcare utilization, compared to any fall occurrence commonly examined in previous studies [13]. We were interested in studying the older adults of low socioeconomic status (SES) because they are at higher risk of falls [14] and suffer from a higher burden of hypertension $[15,16]$. As such, our findings could guide prescribers to exercise extra precaution in the initiation of anti-hypertensive medications or in making medication changes, especially among the older adults of low SES.

\section{Methods}

\section{Study design}

We conducted a nested case-control study involving participants $(N=264)$ taking part in the Integrated Community of Care (ICoC) programme [17], a novel care model in Singapore General Hospital (SGH) that integrates hospital-based transitional care with health and social care in the community. This ongoing programme targets older adults ( $\geq 60$ years old) living in public rental flats, which offer heavily subsidized rents for the underprivileged population, among whom $88 \%$ earn less than S\$670/month (USD498.12 based on SGD1: USD0.74 conversion) [18]. Participants were included in the ICoC programme if they had at least one inpatient and/or outpatient encounter with SGH 3 years prior to entry into the ICoC programme. For those with dementia, they were included if they were capable of independent living or had a caregiver. This study was reviewed and approved by the SingHealth Centralized Institutional Review Board. Written informed consent was obtained for every participant.

We defined cases as participants who experienced any injurious falls from August 2014 to August 2017. For those with multiple injurious falls, we collected information on their baseline characteristics from the most recent injurious fall. For each case, up to 8 controls who had no recorded injurious falls within the same time period were matched on age ( \pm 5 years) and gender. For each control, the fall date of their matched case was taken as the baseline to obtain the relevant independent variables (e.g., medications) 180-day prior to the fall date.

To examine the association between the number of anti-hypertensive medication classes and injurious falls, we identified 48 participants who experienced an injurious fall and 162 matched controls who did not experience any injurious falls during the 3 -year period. An average of 3 controls (minimum $=1$; maximum $=8$ ) were matched to each case on age ( \pm 5 years) and gender.

To examine the association between a change in anti-hypertensive medication and injurious fall, we used the same matching but restricted our sample to include only those who took anti-hypertensive medication. In total, 38 cases and 101 controls were included in this analysis $(N=139)$. An average of 2 controls (minimum $=1$; maximum $=8$ ) were matched to each case on age \pm 5 years) and gender.

\section{Dependent variable of interest}

We defined an injurious fall as a fall that required medical services either in the emergency department or inpatient hospitalisation in SGH. This could be minor injuries such as those that required only dressing and wound cleaning or major injuries such as those that required surgery, casting or resulted in neurological or internal injury.

\section{Exposure variables of interest}

We categorized the number of anti-hypertensive medication classes consumed during the 180-day prior to the fall date into 3 categories: None, 1 class and $\geq 2$ classes of anti-hypertensive medications. 
We considered any anti-hypertensive medications from the following classes - angiotensin converting enzyme inhibitors (ACEI), angiotensin receptor blockers (ARB), beta blockers (BB), calcium channel blockers (CCB) and diuretics. Specifically, the older adults in our sample took enalapril, captopril or lisinopril as ACEI; losartan, valsartan, telmisartan or irbesartan as ARB; atenolol or bisoprolol as BB. amlodipine or slow-release nifedipine as CCB; hydrochlorothiazide, frusemide or spironolactone as diuretics.

We defined a change in anti-hypertensive medication as an addition of a new class of anti-hypertensive medication, an increase in the dosage of the existing medication or a switch to a new class of anti-hypertensive medication. No participants in our study experienced a reduction in dosage or in number of anti-hypertensive medications. Participants who reported no change in anti-hypertensive medication were those who had the same anti-hypertensive medications throughout the 180-day period prior to the fall date or matched fall date.

\section{Data collection}

We reviewed existing literature to determine the information to be collected. All data were collected from SGH medical records for patients, in accordance to the consent provided by the ICoC participants.

For each participant, we collected information on age, gender, body mass index, race, blood pressure and Morse Fall Scale score at the time of the fall. All other baseline characteristics of participants were based on the 180-day prior to the fall date or matched fall date. Information on visual or hearing impairment, prior smoking and alcohol history was also obtained. Cognitive impairment was measured using the Abbreviated Mental Status Test [19] or the Short Portable Mental Status Questionnaire [20]. Both tests consist of 10 items appraising orientation, memory, calculation and facial recognition. The cut-offs for these 2 tests were adjusted according to age and education. Our measure of co-morbidity was the Charlson's Comorbidity Index (CCI) [21], an indicator based on diagnoses of 17 diseases, including myocardial infarction, diabetes and cerebrovascular disease.

Fall risk was assessed using the Morse Fall Scale based on a patient's history of falling, presence of $>1$ medical diagnosis, use of ambulatory aids such as a cane, wheelchair, or walking frame, insertion of intravenous/heparin lock, types of gait and mental status. The scale was validated in Singapore [22] with participants scoring $\geq 55$ considered to be at a high risk of falling. As such, we categorised participants into 2 categories: with and without a high fall risk.

Lastly, we recorded prescription drug name, class, dose, frequency and any change in anti-hypertensive medications during the 180 -day period prior to the most recent fall date. Besides antihypertensive medications, falls could also be attributed to other medications such as psychotropic medications and statins. Psychotropic medications could lead to falls by causing sedation, orthostatic hypotension, confusion, slow reaction times and impaired balance [23] whereas statin therapy could result in a decline in muscle strength [24]. Thus, we also recorded the use of statin and psychotropic medication 180-day prior to the fall date. Psychotropic medications included antidepressant, antipsychotic, sedative-hypnotic, antiepileptic, anti-Parkinson's medication, or narcotic.

We defined polypharmacy as the use of $\geq 4$ chronic medications [25]. We recorded details of all medications dispensed for a period of $\geq 3$ months. This included prescription, non-prescription and over-the-counter (OTC) medication but excluded anti-hypertensive medication to avoid double-counting. We considered fixed-dose combinations (multiple active ingredients in one preparation) as a single medication because we were interested in looking at the pill count rather than the total classes of medication. A higher pill count results in poorer medication adherence which has been associated with an increased rate of falls among older adults [26].

\section{Statistical analysis}

We first summarized the baseline characteristics of participants using means and standard deviations (SDs) or frequencies and percentages. We compared participants who did with those who did not experience any injurious fall using t-tests or Wilcoxon rank-sum tests for continuous variables and Chi-squared or Fisher's exact tests for categorical variables.

Subsequently, we performed conditional logistic regression, using injurious fall as the dependent variable. We began with univariate regression and independent variables with $p<0.10$ were included in the multivariate regression models. We performed two multivariate conditional logistic regressions, using the number of anti-hypertensive medication classes or any change in anti-hypertensive medication as the exposure variables respectively. Associations with $p<0.05$ in the multivariate regressions were regarded as statistically significant. To examine whether the results were consistent in parsimonious models, we also performed sensitivity analyses by including variables with $p<0.10$ into both forward and backward stepwise regressions. We specified $p>0.10$ for removal from the model and $p<0.05$ for addition to the model. We examined all final models for collinearity using variance inflation factor (VIF). All analyses were performed using STATA SE version 14.0 (StataCorp College Station, Texas). 


\section{Results}

\section{Participant characteristics}

Table 1 presents the demographic and clinical characteristics of both cases and controls. The mean $( \pm$ SD) age of the 210 participants was 78.1 ( \pm 8.33$)$ years; $127(60.4 \%)$ were female, 189 (90.0\%) were Chinese. Of the 48 participants who experienced an injurious fall, 44 (91.2\%) experienced minor injuries and 4 (8.33\%) experienced major injuries.

Majority of the participants $(n=148,70.4 \%)$ were on anti-hypertensive medication. Among anti-hypertensive medication users, 76 (51.3\%) took 1 class of medication and $72(48.6 \%)$ took $\geq 2$ classes of medications. No participants in our study took fixed-dose combinations of anti-hypertensive medication. In addition, 41 (27.7\%) participants had a change in anti-hypertensive medication within the 180-day period prior to the fall.

Participants who experienced an injurious fall reported a higher risk of fall, greater use of psychotropic medication, a higher rate of previous falls and a higher proportion with polypharmacy. They were more likely to use walking aids and have a higher mean CCI compared to those that did not experience any injurious fall. In addition, they reported greater use of ACEI, ARB, BB and diuretics.

\section{Association between the number of anti-hypertensive medication classes and injurious falls}

In univariate analysis (Table 2), five variables were associated $(p<0.10)$ with the occurrence of injurious falls: Charlson's Comorbidity Index (OR:1.33; 95\% CI:1.141.56; $p<0.001$ ), high fall risk (OR:5.69; 95\% CI:2.42-13.36; $p<0.001$ ), visual impairment (OR:2.48; 95\% CI:1.01-6.08; $p=0.05$ ), exposure to psychotropic medication (OR:2.21; 95\% CI:0.97-5.06; $p=0.06$ ) and polypharmacy (OR:2.22; 95\% CI:1.08-4.54; $p=0.03$ ). These variables were included as predictors in the multivariate model (Table 2), which showed a significant association between the number of anti-hypertensive medication classes and the odds of experiencing an injurious fall ( $\mathrm{OR}=5.45$; 95\% CI:1.49-19.93; $p=0.01$ ). VIF for each independent variable in the final model was $<5$. While walking aid and prior history of falls had $p<0.10$ in the univariate analyses, they were not included in the multivariate model as they were part of the high fall risk, which we had already adjusted for.

Apart from the exposure variable, the only other variables that reached statistical significance in the multivariate model were Charlson's Comorbidity Index (OR:1.26; 95\% CI:1.04-1.54; $p=0.02$ ) and high fall risk (OR:7.21; 95\% CI:2.37-21.94; $p=0.001$ ). However, the odds ratio of those taking only 1 class of anti-hypertensive medication (OR:2.10; 95 CI:0.48-
9.18; $p=0.33$ ) was not significantly associated with experiencing an injurious fall.

In sensitivity analyses, both forward and backward stepwise regressions yielded identical models (Additional file 1: Table S1). Those on $\geq 2$ anti-hypertensive medication classes had increased odds of experiencing an injurious fall compared to those with no anti-hypertensive medication. The odds ratio was consistent with the main analyses, indicating that our findings were robust. VIF for each independent variable in stepwise regression model was $<5$.

\section{Association between a change in anti-hypertensive medication and injurious falls}

In our univariate analysis (Table 3 ), 3 variables were associated $(p<0.10)$ with the occurrence of injurious falls: Charlson's Comorbidity Index (OR:1.28; 95\% CI:1.08$1.51 ; p=0.004$ ), high fall risk (OR:6.32; 95\% CI:2.1618.46; $p=0.001$ ) and a history of hypertension (OR:0.28; 95 95\% CI:0.07-1.21; $p=0.09)$. After adjusting for Charlson's Comorbidity Index, high fall risk and history of hypertension, any change in anti-hypertensive medication within the 180-day period prior was associated with higher odds of experiencing an injurious fall (OR = 3.88; 95\%CI:1.23-12.19; $p=0.02$ ). VIF for each independent variable in the final model was $<5$.

In our sensitivity analyses, both the forward and backward stepwise regressions yielded identical models (Additional file 1: Table S2). Those who had a recent change in anti-hypertensive medication had higher odds of experiencing an injurious fall compared to those with no change in anti-hypertensive medication (OR:3.66; 95 CI:1.19-11.23; $p=0.01)$. The odds ratio was consistent with that our main analyses, implying that our findings were robust. VIF for each independent variable in the stepwise regression model was $<5$.

\section{Discussion}

We found that older adults with low SES on $\geq 2$ antihypertensive medication classes had higher odds of experiencing an injurious fall compared to those without any anti-hypertensive medication. Among older adults with anti-hypertensive medication, those with a recent change in anti-hypertensive medication also had increased odds of experiencing an injurious fall. These findings contribute to the literature as most existing studies examined the association between anti-hypertensive classes and falls among general community dwelling older adults [13].

Our findings were consistent with an earlier study [9] which quantified treatment intensity using defined daily dose (DDD) and examined any falls as the outcome. Meanwhile, Tinetti et al. that also examined the number of anti-hypertensive medication classes [10] like our study 
Table 1 Baseline characteristics of study participants

\begin{tabular}{|c|c|c|c|c|}
\hline Characteristics & Total sample $(n=210)$ & Cases $(n=48)$ & Controls $(n=162)$ & $P$-value \\
\hline Age, years, mean $\pm S D$ & $78.1 \pm 8.3$ & $79.5 \pm 8.4$ & $77.7 \pm 8.3$ & 0.18 \\
\hline Female, $n(\%)$ & $127(60.4)$ & $32(66.7)$ & $95(58.6)$ & 0.32 \\
\hline Body mass index, $\mathrm{kg} / \mathrm{m}^{2}$, mean $\pm \mathrm{SD}$ & $23.9 \pm 5.2$ & $24.8 \pm 6.0$ & $23.7 \pm 4.8$ & 0.40 \\
\hline Chinese $^{c}, n(\%)$ & $189(90.0)$ & $46(95.3)$ & $143(88.3)$ & 0.17 \\
\hline SBP on admission, $\mathrm{mmHg}$, mean $\pm \mathrm{SD}$ & $133.1 \pm 19.2$ & $137.7 \pm 23.7$ & $131.7 \pm 17.7$ & 0.07 \\
\hline DBP on admission, $\mathrm{mmHg}$, mean $\pm \mathrm{SD}$ & $68.3 \pm 10.3$ & $69.3 \pm 11.8$ & $67.9 \pm 9.9$ & 0.78 \\
\hline Visual impairment, $n$ (\%) & $29(13.8)$ & $10(20.8)$ & $19(11.7)$ & 0.15 \\
\hline Hearing impairment, $n(\%)$ & $18(8.6)$ & $5(10.4)$ & $13(8.02)$ & 0.57 \\
\hline Use of walking aid, $n(\%)$ & $84(40.0)$ & $37(77.1)$ & $47(29.0)$ & $<0.01$ \\
\hline High risk of fall ${ }^{\mathrm{a}}, n(\%)$ & $42(20.0)$ & $21(43.8)$ & $21(13.0)$ & $<0.01$ \\
\hline Smoking history, $n(\%)$ & $48(22.9)$ & $10(20.8)$ & $38(23.4)$ & 0.70 \\
\hline Alcohol history, $n(\%)$ & $23(11.0)$ & $5(10.4)$ & $18(11.1)$ & 0.90 \\
\hline \multicolumn{5}{|l|}{ Medical history, $n(\%)$} \\
\hline Hypertension & $162(77.1)$ & $37(77.1)$ & $125(77.2)$ & 0.88 \\
\hline Cerebrovascular accident or transient ischaemic attack & 39 (18.6) & $12(25.0)$ & $27(16.7)$ & 0.19 \\
\hline Ischaemic heart disease & $52(24.8)$ & $12(25.0)$ & $40(24.7)$ & 0.97 \\
\hline Diabetes mellitus & $75(35.7)$ & $18(37.5)$ & $57(35.2)$ & 0.79 \\
\hline Hyperlipidaemia & $147(70.0)$ & $33(68.8)$ & $114(70.4)$ & 0.83 \\
\hline Osteoporosis & $20(9.5)$ & $5(10.4)$ & $15(9.3)$ & 0.78 \\
\hline Cancer & $26(12.4)$ & $7(14.5)$ & $19(11.7)$ & 0.60 \\
\hline Cognitive impairment & $21(10.0)$ & $6(12.5)$ & $15(9.3)$ & 0.59 \\
\hline Prior history of falls, $n$ (\%) & $49(23.3)$ & $18(37.5)$ & $31(19.1)$ & 0.01 \\
\hline Charlson Comorbidity Index, mean \pm SD & $5.1 \pm 2.3$ & $6.3 \pm 2.5$ & $4.7 \pm 2.1$ & $<0.01$ \\
\hline \multicolumn{5}{|l|}{ Medication use, $n(\%)$} \\
\hline Statin & $124(59.0)$ & $29(60.4)$ & $95(58.6)$ & 0.83 \\
\hline Psychotropic medication & $36(17.1)$ & $13(27.1)$ & $23(14.2)$ & 0.04 \\
\hline Anti-hypertensive medication & $148(70.4)$ & $40(83.3)$ & $108(66.7)$ & 0.03 \\
\hline$\geq 2$ anti-hypertensive medication & $72(34.3)$ & $31(64.6)$ & $41(25.3)$ & $<0.01$ \\
\hline Any change in anti-hypertensive medication ${ }^{b}$ & $41(19.5)$ & $20(41.7)$ & $21(13.0)$ & $<0.01$ \\
\hline \multicolumn{5}{|l|}{ Type of anti-hypertensive, $n(\%)$} \\
\hline Angiotensin-converting enzyme inhibitor & $43(20.5)$ & $15(31.3)$ & $28(17.3)$ & 0.04 \\
\hline Angiotensin II receptor blocker & $41(19.5)$ & $15(31.3)$ & $26(16.0)$ & 0.02 \\
\hline Beta-blocker & $56(26.7)$ & $21(43.8)$ & 35 (21.6) & $<0.01$ \\
\hline Calcium channel blocker & $75(35.7)$ & $17(35.4)$ & $58(35.8)$ & 0.94 \\
\hline Diuretic & $24(11.4)$ & $12(25.0)$ & $12(7.41)$ & $<0.01$ \\
\hline Polypharmacy, n (\%) & 109 (51.9) & $32(66.7)$ & $77(47.5)$ & 0.02 \\
\hline
\end{tabular}

SD Standard deviation, SBP Systolic blood pressure, DBP Diastolic blood pressure

${ }^{\mathrm{a}} \mathrm{High}$ risk of fall $=$ Defined using Morse Fall Scale risk score of 55 or more

${ }^{b}$ Any change in anti-hypertensive medication $=$ An addition of a new class of anti-hypertensive medication or an increase in the dosage of the existing medication or a switch to a new class of anti-hypertensive medication; Polypharmacy $=$ Use of 4 or more chronic medication

Reference group:

'Non-Chinese

found no association between it and injurious falls. This difference in results may be attributable to different study samples as our study examined older adults of low SES who are at higher risk of falls whereas Tinetti et al. examined general community-dwelling older adults [10]. To illustrate it in local context, the proportion of those with hypertension $(162 / 210=77.1 \%)$ and those who experienced falls $(48 / 210=22.9 \%)$ were higher in our study 
Table 2 Association between number of anti-hypertensive medication and injurious falls $(\mathrm{N}=210)$

\begin{tabular}{|c|c|c|c|c|}
\hline & Unadjusted OR (95\% Cl) & P-value & Adjusted OR (95\% Cl) & P-value \\
\hline \multicolumn{5}{|l|}{ Number of anti-hypertensive medication } \\
\hline 0 & 1.00 & & 1.00 & \\
\hline 1 & $0.92(0.30-2.87)$ & 0.89 & $2.10(0.48-9.18)$ & 0.33 \\
\hline$\geq 2$ & $4.75(1.77-12.72)$ & $<0.01$ & $5.45(1.49-19.93)$ & 0.01 \\
\hline Charlson comorbidity index & $1.33(1.14-1.56)$ & $<0.01$ & $1.26(1.04-1.54)$ & 0.02 \\
\hline High risk of fall ${ }^{a}$ & $5.69(2.42-13.36)$ & $<0.01$ & $7.21(2.37-21.94)$ & $<0.01$ \\
\hline Visual impairment & $2.48(1.01-6.08)$ & 0.05 & $2.02(0.70-5.86)$ & 0.19 \\
\hline Exposure to psychotropic medication & $2.21(0.97-5.06)$ & 0.06 & $1.12(0.38-3.37)$ & 0.83 \\
\hline Polypharmacy & $2.22(1.08-4.54)$ & 0.03 & $1.29(0.49-3.43)$ & 0.61 \\
\hline Age (years) & $0.92(0.82-1.04)$ & 0.19 & & \\
\hline $\mathrm{BMI}\left(\mathrm{kg} / \mathrm{m}^{2}\right)$ & $1.06(0.98-1.13)$ & 0.13 & & \\
\hline Chinese $^{c}$ & $2.99(0.62-14.34)$ & 0.17 & & \\
\hline SBP on admission (mmHg) & $1.01(0.99-1.03)$ & 0.13 & & \\
\hline DBP on admission (mmHg) & $1.01(0.98-1.04)$ & 0.52 & & \\
\hline Hearing impairment & $1.27(0.41-3.92)$ & 0.67 & & \\
\hline Use of walking aid ${ }^{b}$ & $8.18(3.29-20.31)$ & $<0.01$ & & \\
\hline Smoking history & $1.06(0.42-2.67)$ & 0.90 & & \\
\hline Alcohol history & $1.13(0.34-3.74)$ & 0.84 & & \\
\hline \multicolumn{5}{|l|}{ Medical history } \\
\hline Hypertension & $1.05(0.47-2.38)$ & 0.90 & & \\
\hline Cerebrovascular accident or transient ischaemic attack & $1.97(0.87-4.49)$ & 0.11 & & \\
\hline Ischaemic heart disease & $1.26(0.57-2.76)$ & 0.56 & & \\
\hline Diabetes mellitus & $1.17(0.60-2.28)$ & 0.65 & & \\
\hline Hyperlipidaemia & $0.91(0.44-1.89)$ & 0.81 & & \\
\hline Osteoporosis & $1.05(0.33-3.32)$ & 0.93 & & \\
\hline Cancer & $1.28(0.48-3.46)$ & 0.62 & & \\
\hline Cognitive impairment & $1.33(0.47-3.80)$ & 0.59 & & \\
\hline Prior history of falls ${ }^{b}$ & $2.51(1.18-5.37)$ & 0.02 & & \\
\hline Statin use & $0.88(0.45-1.71)$ & 0.71 & & \\
\hline
\end{tabular}

OR Odds ratio, CI 95\% confidence interval, SBP Systolic blood pressure, DBP Diastolic blood pressure

${ }^{a}$ High risk of fall = Defined using Morse Fall Scale risk score of 55 or more; Polypharmacy = Use of 4 or more chronic medication

${ }^{b}$ Even though these variables had $p<0.10$ in univariate analysis, they were not included in the multivariate analysis as these variables were part of the high fall risk, which we had already adjusted for

Reference group:

${ }^{\mathrm{C}}$ Non-Chinese

cohort compared to the general older population $(73.9 \%$, $8.2 \%$ respectively) in Singapore [27, 28]. Concurrent administration of $\geq 2$ anti-hypertensive medication classes may increase risk of experiencing an injurious fall by exacerbating postural hypotension or symptoms of dizziness and fatigue [12].

Our literature search only retrieved one study examining the association between a change in anti-hypertensive medication and the risk of experiencing an injurious fall [11]. The study found that long term addition or titration of anti-hypertensive medication was not associated with serious fall injuries. We also included those who switched to a different class of anti-hypertensive medication in our analysis and this might have contributed to the increased risk of experiencing an injurious fall in our study. A change in medication may induce electrolyte disturbances which consequently impairs balance and gait [11] and makes older adults more susceptible to falls.

Our findings have several clinical implications. It is important to be wary of the number of anti-hypertensive medications prescribed to the older population as some older people may be taking more anti-hypertensive 
Table 3 Association between change in anti-hypertensive medication and injurious fall $(N=139)$

\begin{tabular}{|c|c|c|c|c|}
\hline & Unadjusted OR (95\% Cl) & P-value & Adjusted OR $(95 \% \mathrm{Cl})$ & P-value \\
\hline \multicolumn{5}{|l|}{ Any change in anti-hypertensive medication ${ }^{a}$} \\
\hline No & 1.00 & & 1.00 & \\
\hline Yes & $5.66(2.12-15.15)$ & $<0.01$ & $3.88(1.23-12.19)$ & 0.02 \\
\hline Charlson comorbidity index & $1.28(1.08-1.51)$ & $<0.01$ & $1.28(1.04-1.58)$ & 0.02 \\
\hline High risk of fall ${ }^{\mathrm{b}}$ & $6.32(2.16-18.46)$ & $<0.01$ & $5.73(1.60-20.51)$ & 0.01 \\
\hline Visual impairment & $2.10(0.74-6.01)$ & 0.17 & & \\
\hline Exposure to psychotropic medication & $2.07(0.78-5.49)$ & 0.14 & & \\
\hline Polypharmacy & $1.83(0.80-4.19)$ & 0.15 & & \\
\hline Age (years) & $0.90(0.78-1.04)$ & 0.16 & & \\
\hline BMI $\left(\mathrm{kg} / \mathrm{m}^{2}\right)$ & $1.05(0.97-1.14)$ & 0.21 & & \\
\hline Chinese $^{d}$ & $2.10(0.43-10.42)$ & 0.36 & & \\
\hline SBP on admission (mmHg) & $1.00(0.99-1.03)$ & 0.99 & & \\
\hline DBP on admission (mmHg) & $1.00(0.96-1.04)$ & 0.36 & & \\
\hline Hearing impairment & $0.55(0.65-4.75)$ & 0.59 & & \\
\hline Use of walking aid ${ }^{c}$ & $18.07(4.15-78.65)$ & $<0.01$ & & \\
\hline Smoking history & $1.31(0.45-3.76)$ & 0.62 & & \\
\hline Alcohol history & $0.85(0.17-4.31)$ & 0.85 & & \\
\hline \multicolumn{5}{|l|}{ Medical history } \\
\hline Hypertension & $0.28(0.07-1.21)$ & 0.09 & $0.30(0.05-1.75)$ & 0.18 \\
\hline Cerebrovascular accident or transient ischaemic attack & $1.50(0.63-3.59)$ & 0.36 & & \\
\hline Ischaemic heart disease & $0.89(0.39-2.07)$ & 0.79 & & \\
\hline Diabetes mellitus & $0.99(0.46-2.17)$ & 0.99 & & \\
\hline Hyperlipidaemia & $0.77(0.27-2.19)$ & 0.62 & & \\
\hline Osteoporosis & $1.52(0.44-5.20)$ & 0.50 & & \\
\hline Cancer & $1.76(0.61-5.09)$ & 0.30 & & \\
\hline Cognitive impairment & $1.00(0.29-3.45)$ & 1.00 & & \\
\hline Prior history of falls & $1.84(0.79-4.30)$ & 0.16 & & \\
\hline Statin use & $0.50(0.21-1.18)$ & 0.12 & & \\
\hline
\end{tabular}

OR Odds ratio, CI 95\% confidence interval, SBP Systolic blood pressure, DBP Diastolic blood pressure

${ }^{a}$ Any change in anti-hypertensive medication = An addition of a new class of anti-hypertensive medication or an increase in the dosage of the existing medication or a switch to a new class of anti-hypertensive medication

${ }^{b}$ High risk of fall = Defined using Morse Fall Scale risk score of 55 or more.; Polypharmacy = Use of 4 or more chronic medication

'Even though this variable had $\mathrm{p}<0.10$ in univariate analysis, it was not included in the multivariate analysis as these variables were part of the high fall risk, which we had already adjusted for

Reference group:

${ }^{\mathrm{d}}$ Non-Chinese

medication than needed [29]. Prescribers should develop patient-specific treatment goals and avoid "over-treatment" of hypertension, particularly among older population of low SES. A recent study by Zia et al. [30] showed that the consumption of two or more fall risk increasing drugs (FRID) is a significant predictor for falls. Anti-hypertensive medication was identified to be one of the many FRIDs. As such, it is imperative that healthcare providers discuss risk and preventative strategies for falls with patients when commencing anti-hypertensive medications or when adding, switching or increasing the dose of antihypertensive medications.

The findings from this study should be interpreted within the context of the following limitations. We defined "injurious falls" based on healthcare use [31], specifically falls requiring medical services as we were concerned about healthcare utilization resulting from falls. We acknowledge that there are other definitions of "injurious falls" in literature [31] such as those based on symptoms only (e.g. fractures) or a combination of symptoms and healthcare use. Therefore, our 
findings may not be generalizable to other definitions of "injurious falls". We checked for confounding for a wide array of conditions and medications associated with falls and adjusted for the appropriate variables in multivariate analyses. However, we acknowledge there is still a possibility of residual confounding as our study lacked information on important variables such as frailty and blood pressure. Previous study [32] found substantial differences in the associations between cardiovascular medication use and fall risk in frail and robust older adults. In addition, as blood pressure measurements immediately prior to falls were not available, we were unable to ascertain whether the falls were due to orthostatic hypotension resulting from anti-hypertensive medications.

We also did not collect any measures of adherence to anti-hypertensive medication. Nevertheless, we note that non-adherence would result in underestimation of a true effect. We did not consider the dose of each anti-hypertensive medication. As such, we could not attribute our findings to the dose intensity of each medication. Due to the small samples, our analyses were unable to account for specific type and class of anti-hypertensive medications. Lastly, although the small sample size and the small number of injurious fallers in our study may have posed some challenges, such as imprecise estimates and potentially the sample is not representative of the population, our findings from both the main and sensitivity analyses were consistent.

\section{Conclusion}

In a nutshell, our study demonstrated that $\geq 2$ antihypertensive medication classes and a change in antihypertensive medication were associated with an increased risk of injurious falls among older adults of low SES. Prescribers should design patient-specific treatment goals to prevent the "over-treatment" of hypertension. In addition, the risk of and preventative strategies for falls should be discussed with patients when commencing anti-hypertensive medications or when adding, switching or increasing the dose of anti-hypertensive medications, especially among older adults of low SES who are more prone to falling.

\section{Additional file}

Additional file 1: Results of sensitivity analyses. The file contains two tables (Tables S1 and S2) presenting the results of the sensitivity analyses (stepwise regression). (DOCX $17 \mathrm{~kb}$ )

\section{Abbreviations}

ACEi: Angiotensin converting enzyme inhibitors; ARB: Angiotensin receptor blockers; BB: Beta blockers; CCB: Calcium channel blockers; CCl: Charlson's co-morbidity index; DDD: Defined-daily dose; FRID: Fall risk increasing drugs; ICOC: Integrated Community of Care programme; OR: Odds ratio; OTC: Over-the-counter; SD: Standard deviation; SES: Socio-economic status; SGD: Singapore Dollar; SGH: Singapore General Hospital; USD: United States Dollar; VIF: Variance inflation factor

\section{Acknowledgements}

We would like to acknowledge the Integrated Community of Care project team for their effort in recruiting participants.

\section{Funding}

There was no external funding for this study. The ICoC study was originally supported by the SingHealth Regional Health System and Duke-NUS Medical School Centre for Aging Research and Education.

Availability of data and materials

The datasets used and/or analysed during the current study are available from the corresponding author on reasonable request.

\section{Authors' contributions}

LLL is the principal investigator of the study. LLL and KZY conceptualized the study. TO, KHL, JT and WF advised the study design. ZB and HTA collected the data, supervised by KKL, YHK and KZY. CST and YHK advised the statistical analyses. ZB and KKL performed the analyses. TO, KHL, JT and WF assisted in the interpretations of the findings. $\mathrm{ZB}$ and $\mathrm{KKL}$ prepared the first draft of the manuscript. All co-authors critically reviewed and agreed to the final content of the manuscript before submission. All authors read and approved the final manuscript.

\section{Ethics approval and consent to participate}

This study was reviewed and approved by the SingHealth Centralized Institutional Review Board. Written informed consent was obtained for every participant.

Consent for publication

Not applicable.

\section{Competing interests}

The authors declare that they have no competing interests.

\section{Publisher's Note}

Springer Nature remains neutral with regard to jurisdictional claims in published maps and institutional affiliations.

\section{Author details}

${ }^{1}$ Department of Pharmacy, Faculty of Science, National University of Singapore, Singapore, Republic of Singapore. ${ }^{2}$ Program in Health Services and Systems Research, Duke-NUS Medical School, Singapore, Republic of Singapore. ${ }^{3}$ Saw Swee Hock School of Public Health, National University of Singapore and National University Health System, Singapore, Republic of Singapore. ${ }^{4}$ Department of Family Medicine and Continuing Care, Singapore General Hospital, Singapore, Republic of Singapore. ${ }^{5}$ Department of Rheumatology and Immunology, Singapore General Hospital, Singapore, Republic of Singapore. ${ }^{6}$ Duke-NUS Medical School, Singapore, Republic of Singapore. ${ }^{7}$ Department of Medicine, Yong Loo Lin School of Medicine, National University of Singapore, Singapore, Republic of Singapore.

Received: 3 April 2018 Accepted: 6 August 2018

Published online: 28 August 2018

References

1. World Health Organization. WHO Global Report on Falls Prevention in Older Age. Geneva: World Health Organization; 2007.

2. Tinetti ME, Doucette J, Claus E, Marottoli R. Risk factors for serious injury during falls by older persons in the community. J Am Geriatr Soc. 1995; 43(11):1214-21.

3. Chan K, Pang W, Ee CH, Ding Y, Choo P. Epidemiology of falls among the elderly community dwellers in Singapore. Singap Med J. 1997;38(10):427-31.

4. Cumming RG, Salkeld G, Thomas M, Szonyi G. Prospective study of the impact of fear of falling on activities of daily living, SF-36 scores, and nursing home admission. J Gerontol A Biol Sci Med Sci. 2000;55(5):M299-305.

5. Hartholt KA, Polinder S, Van der Cammen TJ, Panneman MJ, Van der Velde $\mathrm{N}$, Van Lieshout EM, et al. Costs of falls in an ageing population: a nationwide study from the Netherlands (2007-2009). Injury. 2012;43(7): 1199-203. 
6. Wiens M, Etminan M, Gill SS, Takkouche B. Effects of antihypertensive drug treatments on fracture outcomes: a meta-analysis of observational studies. J Intern Med. 2006;260(4):350-62.

7. Leipzig RM, Cumming RG, Tinetti ME. Drugs and falls in older people: a systematic review and meta-analysis: II. Cardiac and analgesic drugs. J Am Geriatr Soc. 1999:47(1):40-50.

8. Zang G. Antihypertensive drugs and the risk of fall injuries: a systematic review and meta-analysis. J Int Med Res. 2013;41(5):1408-17.

9. Callisaya ML, Sharman JE, Close J, Lord SR, Srikanth VK. Greater daily defined dose of antihypertensive medication increases the risk of falls in older people-a population-based study. J Am Geriatr Soc. 2014;62(8):1527-33.

10. Tinetti ME, Han L, Lee DS, McAvay GJ, Peduzzi P, Gross CP, et al. Antihypertensive medications and serious fall injuries in a nationally representative sample of older adults. JAMA Intern Med. 2014;174(4):588-95.

11. Shimbo D, Barrett Bowling C, Levitan EB, Deng L, Sim JJ, Huang L, et al. Short-term risk of serious fall injuries in older adults initiating and intensifying treatment with antihypertensive medication. Circ Cardiovasc Qual Outcomes. 2016;9(3):222-9.

12. Milazzo VSC, Servo S, Crudo V, Fulcheri C. Drugs and Orthostatic Hypotension: Evidence from Literature. J Hypertens. 2012;1(104). https:// www.omicsonline.org/open-access/drugs-and-orthostatic-hypotensionevidence-from-literature-2167-1095.1000104.php?aid=6762.

13. Ang HT, Lim KK, Kwan YH, Tan PS, Yap KZ, Banu Z, et al. A Systematic Review and Meta-Analyses of the Association Between Anti-Hypertensive Classes and the Risk of Falls Among Older Adults. Drugs Aging. 2018;35(7): 625-35. https://link.springer.com/article/10.1007\%2Fs40266-018-0561-3.

14. Gill T, Taylor AW, Pengelly A. A population-based survey of factors relating to the prevalence of falls in older people. Gerontology. 2005;51(5):340-5.

15. Beverly H, Brummett MAB, llene C, Siegler MS, Harris KM, Elder GH, Williams RB. Systolic blood pressure, socioeconomic status, and biobehavioral risk factors in a nationally representative US young adult sample. Hypertension. 2011;58:161-6.

16. Lam CSP. The socioeconomics of hypertension. Hypertension. 2011;58:140-1.

17. Low LL, Maulod A, Lee KH. Evaluating a novel Integrated Community of Care (ICOC) for patients from an urbanised low-income community in Singapore using the participatory action research (PAR) methodology: a study protocol. BMJ Open. 2017;7(10):e017839. https://bmjopen.bmj.com/content/7/10/e017839.info.

18. Housing \& Development Board. Public housing in Singapore: residents' profile, hosuing satisfaction and preferences: HDB sample household survey 2013. Published by: Housing \& Development Board. Year published: 2014. Country: Singapore. https://www.hdb.gov.sg/cs/infoweb/monograph-1-29-dec-2014.

19. Sahadevan S, Lim PP, Tan NJ, Chan SP. Diagnostic performance of two mental status tests in the older chinese: influence of education and age on cut-off values. Int J Geriatr Psychiatry. 2000;15(3):234-41.

20. Malhotra C, Chan A, Matchar D, Seow D, Chuo A, Do YK. Diagnostic performance of short portable mental status questionnaire for screening dementia among patients attending cognitive assessment clinics in Singapore. Ann Acad Med Singap. 2013;42(7):315-9.

21. Charlson's ME, Pompei P, Ales KL, MacKenzie CR. A new method of classifying prognostic comorbidity in longitudinal studies: development and validation. J Chronic Dis. 1987;40(5):373-83.

22. Yuh AS, Perera $K$, Yunn R. Evidence-based management of patients risk for falls in the inpatient setting. Publisher: Singapore Healthcare Management Conference; 2013. [Accessed 03 March 2018; Last Update 2015]. http://www. singaporehealthcaremanagement.sg/Abstracts/Documents/PDFs/ RM0002\%20-\%20Ang\%20Shin\%20Yuh.pdf.

23. de Jong MR, Van der Elst M, Hartholt KA. Drug-related falls in older patients: implicated drugs, consequences, and possible prevention strategies. Ther Adv Drug Saf. 2013;4(4):147-54.

24. Scott D, Blizzard L, Fell J, Jones G. Statin therapy, muscle function and falls risk in community-dwelling older adults. QJM. 2009;102(9):625-33.

25. Bor A, Matuz M, Csatordai M, Szalai G, Bálint A, Benkő R, et al. Medication use and risk of falls among nursing home residents: a retrospective cohort study. Int J Clin Pharm. 2017;39(2):408-15.

26. Berry SD, Quach L, Procter-Gray E, Kiel DP, Li W, Samelson EJ, et al. Poor Adherence to Medications May Be Associated with Falls. J Gerontol A Biol Sci Med Sci. 2010;65a(5):553-8.

27. Malhotra R, Chan A, Malhotra C, Ostbye T. Prevalence, awareness, treatment and control of hypertension in the elderly population of Singapore. Hypertens Res. 2010;33(12):1223-31.

28. Yeo YY, Lee SK, Lim CY, Quek LS, Ooi SB. A review of elderly injuries seen in a Singapore emergency department. Singap Med J. 2009;50(3):278-83.
29. Mancia G, Fagard R, Narkiewicz K, Redon J, Zanchetti A, Bohm M, et al. 2013 ESH/ESC guidelines for the management of arterial hypertension: the task force for the management of arterial hypertension of the European Society of Hypertension (ESH) and of the European Society of Cardiology (ESC). J Hypertens. 2013;31(7):1281-357.

30. Zia A, Kamaruzzaman SB, Tan MP. The consumption of two or more fall riskincreasing drugs rather than polypharmacy is associated with falls. Geriatr Gerontol Int. 2017;17(3):463-70.

31. Schwenk M, Lauenroth A, Stock C, Moreno RR, Oster P, McHugh G, et al. Definitions and methods of measuring and reporting on injurious falls in randomised controlled fall prevention trials: a systematic review. BMC Med Res Methodol. 2012;12(1):50.

32. Peeters G, Tett SE, Hollingworth SA, Gnjidic D, Hilmer SN, Dobson AJ, et al. Associations of guideline recommended medications for acute coronary syndromes with fall-related hospitalizations and cardiovascular events in older women with ischemic heart disease. J Gerontol A Biol Sci Med Sci. 2017;72(2):259-65.

\section{Ready to submit your research? Choose BMC and benefit from:}

- fast, convenient online submission

- thorough peer review by experienced researchers in your field

- rapid publication on acceptance

- support for research data, including large and complex data types

- gold Open Access which fosters wider collaboration and increased citations

- maximum visibility for your research: over $100 \mathrm{M}$ website views per year

At BMC, research is always in progress.

Learn more biomedcentral.com/submissions 